\title{
Sarcopenia-A baby boomers dilemma for nurse practitioners to discover, diagnose, and treat
}

\author{
Kelley L. Jackson*1, Dennis Hunt ${ }^{2}$, Deborah Chapa ${ }^{3}$, Sareen S. Gropper ${ }^{1}$ \\ ${ }^{1}$ Christine E. Lynn College of Nursing, Florida Atlantic University, Boca Raton, FL, United States \\ ${ }^{2}$ Rehabilitation Sciences, Florida Gulf Coast University, Fort Myers, FL, United States \\ ${ }^{3}$ Lee Memorial Health System, Fort Myers, FL, United States
}

Received: December 21, 2017

DOI: $10.5430 /$ jnep.v8n9p77
Accepted: April 15, 2018

Online Published: April 25, 2018

\begin{abstract}
Objective: Sarcopenia is a disease of low skeletal muscle mass and strength that occurs with aging. It is most commonly seen in individuals aged 50 years and over. Nurse practitioners can take a proactive approach to the understanding and screening of this disease in attempts to prolong its onset or to treat the condition before it leads to additional adverse consequences.

Methods: A comprehensive review of the literature, including evidence-based literature from peer-reviewed articles, including randomized controlled trials, was conducted.

Results: This review of the literature indicated patients can benefit greatly from nurse practitioner's awareness and intervention by screening for sarcopenia as well as offering appropriate education and treatment to their patients. Once a diagnosis is reached, the nurse practitioner can then collaborate with other disciplines such as nutrition, medicine, exercise physiology and/or physical therapy to develop an intervention strategy that can treat or prevent this condition before it leads to decreased independence, early onset disability and decreased quality of life, among other adverse health outcomes.

Conclusions: There is a call to action on the part of nurse practitioners in efforts to prevent and/or slow the onset of age-related sarcopenia and its adverse consequences.
\end{abstract}

Key Words: Sarcopenia, Aging, Muscle, Prevention, Diagnosis, Treatment, Adverse outcomes

\section{INTRODUCTION}

An ICD-10 diagnosis code, M62.84, was awarded for sarcopenia in the United States in late 2016. ${ }^{[1]}$ With the establishment of this code and its use by practitioners, practitioners and patients need key information about diagnosis, prevention and treatment of sarcopenia. Muscles make up 40 to $50 \%$ of the body's mass and are critical for activities of daily living, functional independence, and quality of life. Sarcopenia, taken from the Greek language, literally means "poverty of flesh"[2] to describe the loss of skeletal muscle mass that occurs with aging. The rate of muscle mass loss with aging has been estimated at $6 \%$ per decade beginning at about 50 years of age, ${ }^{[3,4]}$ and estimates of muscle strength loss range from 10 to $15 \%$ per decade between ages 50 to 70 years, after which time this loss accelerates to $25 \%$ to $40 \%$ per decade. ${ }^{[5,6]}$

\section{Background and significance}

While sarcopenia has been most consistently characterized by the loss of muscle mass by most professional organizations, the condition is now more commonly characterized by reduc-

\footnotetext{
* Correspondence: Kelley L. Jackson; Email: kjackson2016@health.fau.edu; Address: Christine E. Lynn College of Nursing, Florida Atlantic University, Boca Raton, FL 33431, United States.
} 
tions in not only muscle mass, but also muscle strength and/or function. The European Working Group on Sarcopenia in Older People (EWGSOP), for example, defines sarcopenia as a syndrome characterized by progressive and generalized loss of skeletal muscle mass and strength with a risk of adverse outcomes such as physical disability, poor quality of life, and death. ${ }^{[7,8]}$ The International Working Group on Sarcopenia (IWGS) defines sarcopenia as the age-associated loss of skeletal muscle mass and function. ${ }^{[9]}$ Additional definitions also include declines in muscle strength and/or function. ${ }^{[10-12]}$

These differences in definitions have contributed to considerable variations in the estimates of the prevalence of sarcopenia. Additionally, an accurate reporting of the prevalence of sarcopenia continues to be challenging due to differences in the methods used to assess muscle mass and in cutoff values used for diagnosis, and due to variability among study populations such as those who are generally healthy, frail, or have comorbidities. ${ }^{[13]}$ Data from the United States National Health and Nutrition Examination Survey (NHANES) III, which included a large sample of over 4,500 adults aged 60 years and older from multiple ethnicities, found that $59 \%$ of women and $45 \%$ of men had sarcopenia. ${ }^{[14]}$ These prevalence figures are based on the skeletal muscle mass index which is calculated as skeletal muscle mass (attained using bioelectrical impedance analysis) divided by body mass times 100 , and then compared with gender-specific values from younger adults (aged 18 to 39 years) in an approach similar to that used to diagnose osteoporosis. Other approaches used to estimate the prevalence and to diagnose sarcopenia divide muscle mass (attained typically by bioelectrical impedance analysis or by dual x-ray absorptiometry) by height ${ }^{2}$ or by body mass index (BMI). As a consequence of these differences, prevalence reports for sarcopenia range from about 1 to $85 \%$ in the scientific literature. ${ }^{[13,15,16]}$

Yet, while the exact prevalence of sarcopenia among older adults in the United States is not clear, the condition is costly to treat. In the United States, in 2000, the estimated direct health care cost attributable to sarcopenia was 18.5 billion. ${ }^{[14]}$ It has been estimated that as little as a $10 \%$ reduction in the prevalence of sarcopenia has the potential to save $\$ 1.1$ billion in U.S. health care costs. ${ }^{[17]}$ However, the costs of sarcopenia and the savings from its prevention are considerably higher should the condition result in frailty, falls, and other adverse events. ${ }^{[18]}$ Sarcopenia has profound adverse effects on health. The goals of this review are to provide the nurse practitioner with an awareness and appreciation for sarcopenia and its potential impact on health and to provide practical approaches for screening, and prevention and management.

\section{AdvERSE OUTCOMES}

\subsection{Decreased physical function}

Sarcopenia decreases physical function and promotes early onset disability resulting in decreased independence, functional limitations, and reduced quality of life. ${ }^{[19,20]}$ In a study of 4,504 adults $\geq 60$ years of age, men with low skeletal muscle mass were approximately two times and women with low skeletal muscle mass were about three times more likely to exhibit functional impairment and disability when compared with adults with normal skeletal muscle mass. ${ }^{[14]}$ Further, in a study of 1,750 community-dwelling men aged 70 years and over, loss of muscle strength was significantly correlated with physical disability in independent activities of daily living and functional limitation. ${ }^{[10]}$ Data from the Honolulu Heart Program, which included 3,218 adults, found that higher handgrip muscle strength in participants assessed during middle age adulthood was inversely associated with the presence of disabilities, regardless of the diseases that may have developed 25 years later at follow-up. ${ }^{[21]}$

\subsection{Falls, frailty, and mortality \\ 2.2.1 Falls}

Falls occur frequently in adults over the age of 65 years, with one-in-three older adults falling annually. ${ }^{[22]}$ Sarcopenia increases the risk for falls as well as fractures in older adults. ${ }^{\text {[23] }}$ In a study of over 1,600 men and women aged 55-98 years, men with sarcopenia were two times as likely to have fallen in the past year versus those without sarcopenia. ${ }^{[24]}$ Another study of 2,148 older adults aged 59-73 years also reported that falls were inversely related to muscle strength in men and women. ${ }^{[25]}$ A small study of women presenting with hip fractures reported more extensive atrophy in the vastus lateralis muscle than similar aged healthy women. ${ }^{[26]}$

\subsubsection{Frailty}

Sarcopenia also contributes to frailty, with reductions in muscle strength considered as a component of the condition. Frailty is typically diagnosed based on the presence of at least three of five following components-weight loss of $>$ $4.5 \mathrm{~kg}$ in the past year, exhaustion, physical inactivity, low walking speed, and reduced muscle strength (assessed from handgrip strength measurements). ${ }^{[27]}$ Both higher muscle mass and muscle quality were found to be inversely associated with frailty in the Invecchaire in Chianti study which included 81 participants aged 69 to 81 years. ${ }^{[28]}$

\subsubsection{Mortality}

Mortality is also higher among older adults with low muscle mass and strength. Using results from NHANES III data, which included a sample of over 4,500 adults age 60 years and older, women with sarcopenia (after adjusting for comorbidities) were found to have a higher mortality risk than those 
without sarcopenia. ${ }^{[16]}$ Landi et al., ${ }^{[29]}$ in a 7-year follow-up study of 197 participants with a mean age of 85 years, found that those who had been diagnosed with sarcopenia had a higher mortality rate (independent of age and other clinical and functional variables) than those without sarcopenia.

\subsection{Hospitalizations, postoperative complications, length of stay, and rehospitalization rates}

Individuals with sarcopenia are more likely to be hospitalized, and or be placed in nursing homes when compared with individuals without sarcopenia; increased medical costs and mortality also result. ${ }^{[18]}$ Hospitalized patients with sarcopenia are also at increased risk of postoperative complications, an increased length of hospital stay, ${ }^{[30]}$ and higher rehospitalization rates than those without sarcopenia. ${ }^{[31-33]}$ A study of 127 older adults undergoing oral surgery found that individuals with decreased muscle strength developed significantly more postoperative complications than those with adequate muscle strength. ${ }^{[34]}$ A study of 205 patients undergoing general surgery also found that those with decreased muscle strength developed significantly more postoperative complications and had increased length of hospital stay than the patients with adequate muscle strength. ${ }^{[35]}$ Additionally, higher muscle strength on admission has been associated with increased likelihood of discharge to usual residence in a study of 120 older adults. ${ }^{[36]}$

\subsection{Disease outcomes}

The presence of reduced muscle mass also affects outcomes in individuals with conditions such as cancer, as well as heart, renal, and respiratory diseases.

\subsubsection{Cancer}

Individuals with comorbidities such as cancer are less likely to tolerate some treatment options if they also have low muscle mass. For example, in a study of patients with non-small cell lung cancer receiving chemotherapy, patients with low lean body mass and low BMI had a higher incidence of doselimiting toxicity compared to those with higher lean body mass and BMI. ${ }^{[37]}$ Another study also showed that cancer patients who were considered sarcopenic had a greater potential to develop toxicities related to the chemotherapy regimen than those with adequate lean body mass. ${ }^{[38]}$ Similar findings have been demonstrated in patients with colon cancer. ${ }^{[39]}$

\subsubsection{Heart, renal, and respiratory diseases}

Sarcopenia is also associated with adverse outcomes in patients diagnosed with cardiovascular disease and heart failure. ${ }^{[40-42]}$ In a study examining body composition and 3-year mortality in patients with heart disease, individuals with stable heart disease and low lean body mass had a $15 \%$ increase in mortality compared to those individuals with a higher lean body mass. ${ }^{[41]}$ Similar findings have been reported in patients diagnosed with renal failure. ${ }^{[43-45]}$ In an observational study of 14,632 hemodialysis patients, those with lower BMI as well as muscle mass and/or unintentional weight or muscle loss exhibited a $20 \%$ higher death risk when compared with patients whose weight remained stable. ${ }^{[46]}$

Sarcopenia is also associated with adverse outcomes in patients diagnosed with chronic obstructive pulmonary disease (COPD). A study of 622 patients with stable COPD found that those with sarcopenia were more likely to exhibit impaired function and health status. ${ }^{[47]}$ A study of 1,898 patients with COPD from the Copenhagen City Heart Study found that both low fat-free mass and BMI were significant predictors of mortality; ${ }^{[48]}$ however, Marquis et al. ${ }^{[49]}$ showed that mid-thigh muscle cross-sectional area was a better predictor of mortality than BMI.

In summary, an evaluation of the literature examining sarcopenia and health outcomes clearly demonstrates multiple adverse effects including decreased independence, early onset disability, and functional limitations as well as higher risks of falls, frailty, and mortality. Moreover, in hospitalized patients, sarcopenia is associated with increased risk of postoperative complications and increased length of stay as well as higher rates of hospitalization and mortality. In patients with co-morbid conditions, such as cancer and heart, renal, and respiratory diseases, reduced muscle mass is also associated with increased mortality.

\section{SCREENING \& DiAgNosis}

The clinical implications from the loss of muscle mass, strength, and/or function in older adults clearly emphasize a need for prevention and for screening, especially in those with risk factors.

\subsection{Screening}

The SARC-F questionnaire is a short screening tool developed specifically for sarcopenia that is available for use in community-dwelling older adults. ${ }^{[50,51]}$ The five-item, selfreported questionnaire addresses: strength (S) by asking about difficulty lifting and carrying $10 \mathrm{lbs}$.; assistance (A) by asking about difficulty walking across the room; rise (R) by asking about difficulty transferring from a chair or bed; climb (C) by asking about difficulty climbing a flight of 10 stairs; and falls (F) by asking about how many times the person has fallen in the last year. Scores for each question range from 0 to 2 with a total score of 4 or higher indicating risk for sarcopenia. ${ }^{[50,51]}$

At present, no other screening tools for sarcopenia are available. However, several tools are available for malnutrition, 
and malnutrition is frequently identified by unintentional loss of weight (which includes muscle mass loss), or by low BMI $\left(<18.5 \mathrm{~kg} / \mathrm{m}^{2}\right)$, which also may indicate low muscle mass. And, because screening and assessment tools used for malnutrition typically include information on weight loss and/or BMI, the use of such tools to identify sarcopenia may be helpful. Moreover, malnutrition is fairly common among older adults, affecting about $5 \%$ to $30 \%$ of those living in the community and up to $50 \%$ in hospital settings. ${ }^{[52]}$

Two widely used and accepted screening tools, which have been tested for validity and reliability, are the MiniNutritional Assessment - short form (MNA-SF) and the Malnutrition Universal Screening Tool (MUST). ${ }^{[53]}$ Table 1 provides information on each of these screening tools. The MNA-SF is used for screening older adults in community settings, but has also been validated for use in in-patient hospital settings. ${ }^{[54-58]}$ MUST is also commonly used and has been validated in community as well as in in-patient hospital settings. ${ }^{[57,59,60]}$

For nutritional diagnosis and the initiation of nutrition support of malnutrition, the full Mini-Nutritional Assessment (MNA) and the subjective global assessment (SGA) are widely used. The full (18-item) MNA, which has been validated in community, hospital, and long-term care settings, consists of the six-item screening that is part of the MNA-SF screen along with 12 additional items. ${ }^{[58]}$ The SGA, also demonstrated to be valid and reliable for the assessment of nutritional status in older adults in hospitals and other clinical settings as well as for malnutrition-related muscle dysfunction, consists of two parts - a medical history and physical exam, described further in Table $1 .{ }^{[57,61-63]}$ The physical exam component of the SGA assesses for subcutaneous fat loss, muscle wasting, and the presence of fluid retention (i.e. malnutrition-related edema and ascites). This identification of muscle wasting as part of the physical examination of the SGA may also be used in conjunction with measurements of muscle strength or alone to assist in the identification of sarcopenia.

\subsection{Diagnosis}

\subsubsection{Physical exam}

The physical examination used in the diagnosis of malnutrition, ${ }^{[64]}$ but which also may be applicable to diagnose muscle loss indicative of sarcopenia, focuses on the identification of muscle wasting. ${ }^{[61,62]}$ With malnutrition, loss of muscle mass typically occurs first in the upper and then in the lower body. However, both areas should be examined. In the lower body, the calf, knee and thigh areas should be examined for diminished quadriceps femoris and gastrocnemius mass. ${ }^{[62,65]}$ In the hands, observe for flattened or depressed areas and palpate for signs of dorsal interosseous muscle wasting. In the shoulders, which are normally rounded at the junctions of the shoulder and neck and the shoulder and arm, protrusion or prominence of the acromion process, indicating loss of the deltoid muscle, should be documented. Observation of the trunk should focus on the ribs, noting any protrusion or prominence. Additionally, observe and document significant protrusion of the scapula, which suggests loss of the trapezius and latissimus dorsi muscles. ${ }^{[62]}$ Around the temples, a hollowing or scooping appearance of the temporalis muscle with a prominent brow bone also may suggest malnutrition.

\subsubsection{MUAC}

In addition to the physical examination, the mid-upper arm circumference (MUAC) measurement has been shown to correlate positively and significantly with BMI in hospitalized patients. ${ }^{[65]}$ For those patients for whom height and weight cannot be measured, a MUAC cut-point of $<22.5 \mathrm{~cm}$ has been shown to correlate with a BMI $<18.5 \mathrm{~kg} / \mathrm{m}^{2}{ }^{[66]}$ MUAC has also been used alone or in combination with calf measurements to assess for loss of muscle and malnutrition. ${ }^{[65-67]}$ A cloth measuring tape is used to determine MUAC (in $\mathrm{cm}$ ) with the tape placed around the bicep muscle at the midpoint between the acromion and olecranon processes.

\subsubsection{Handgrip strength}

Diminished muscle strength, also indicative of sarcopenia, can be easily and fairly quickly measured in clinical settings by assessing handgrip strength and by a chair stand test. Handgrip strength, measured using a hand dynamometer, indicates upper limb muscle strength; it is highly correlated with quadriceps strength and lower extremity strength. ${ }^{[68]}$ Cut-off values suggestive of poor muscle strength, published as part of the Foundation for the National Institutes of Health Sarcopenia Project, are $<26 \mathrm{~kg}$ for men and $<16 \mathrm{~kg}$ for women. ${ }^{[69]}$

\subsubsection{Chair stand test}

The chair stand test provides a strong measure of lower extremity function including lower body strength, power, coordination, and balance and is suggested as an effective screening tool for sarcopenia. ${ }^{[70-72]}$ The technique requires a count of the number of chair-stands completed in 30 seconds or may be done by recording the time that it takes for a person to complete five chair-stands (without hand assistance from a straight back chair, without an armrest and with a seat height of 17 inches). A count that is less than age- and gender-specific norms in 30 seconds (for example, $<12$ for women and $<14$ for men aged 60 to 64 years) is suggestive of poor muscle strength, or a time to complete the five chair-stands that exceeds 13.6 seconds is suggestive of poor muscle strength and risk for sarcopenia. ${ }^{[71-73]}$ 


\subsubsection{Gait speed and timed up and go test}

Diminished muscle performance can also be evaluated in clinical settings through an assessment of gait speed or from a timed up and go (TUG) test. Usual gait speed is timed from a 4-meter walk test which can be set up in a hallway or examination room; cut-off values of $<1$ meter/second $(\mathrm{m} / \mathrm{s})$ (as well as $<0.8 \mathrm{~m} / \mathrm{s}$ ) are suggestive of diminished muscle function. ${ }^{[9,74]}$ The timed up and go test measures the time (in seconds) that it takes to stand up from a seated position in a chair, walk 3 meters away from the chair at a comfortable pace to a line on the floor, turn around, walk back, and sit back down in the chair. Times are compared with age-specific norms with healthy older adults generally completing the test in less than 10 seconds. ${ }^{[73,75]}$

Table 1. Some approaches to assess and diagnose malnutrition in older adults

\begin{tabular}{|c|c|c|}
\hline Tool & Parameters & Scoring \\
\hline $\begin{array}{l}\text { Mini-Nutritional } \\
\text { Assessment-short form } \\
\text { (MNA-SF)-screening }\end{array}$ & $\begin{array}{l}\text { 6-food intake, weight loss, mobility, the presence of } \\
\text { clinical conditions (psychological stress and/or acute } \\
\text { disease, neuropsychological conditions), and BMI (or, if } \\
\text { BMI is not available, calf circumference). }\end{array}$ & $\begin{array}{l}\text { Maximum score } 14 \\
12-14 \text { not at risk for malnutrition } \\
8-11 \text { at risk for malnutrition and in } \\
\text { need of assessment } \\
0 \text { to } 7 \text { malnourished }\end{array}$ \\
\hline $\begin{array}{l}\text { Malnutrition Universal } \\
\text { Screening Tool } \\
\text { (MUST)-screening }\end{array}$ & $\begin{array}{l}\text { 3-BMI (with }<20 \mathrm{~kg} / \mathrm{m}^{2} \text { indicating risk), weight history } \\
\text { (i.e. unintentional weight loss over the past 3-6 months), } \\
\text { and illness affecting oral food intake. }\end{array}$ & $\begin{array}{l}\text { Maximum score } 3 \\
0 \text { not at risk for malnutrition } \\
1 \text { medium risk malnutrition } \\
2 \text { or more high risk malnutrition }\end{array}$ \\
\hline $\begin{array}{l}\text { Mini-Nutritional } \\
\text { Assessment-original } 18 \\
\text { item (MNA)-assessment }\end{array}$ & $\begin{array}{l}6 \text { parameters listed in MNA-SF plus } 12 \text { additional } \\
\text { parameters including anthropometric assessment (midarm } \\
\text { and calf circumferences), general assessment (number of } \\
\text { prescription medications, living independently, presence } \\
\text { of pressure ulcers), dietary assessment (number of meals } \\
\text { eaten daily, protein sources, fruit, vegetable, and fluid } \\
\text { intake, ability to feed themselves), and self-assessment } \\
\text { (nutritional and health status). }\end{array}$ & $\begin{array}{l}\text { Maximum score } 30 \\
17-23.5 \text { risk for malnutrition } \\
<17 \text { malnourished }\end{array}$ \\
\hline $\begin{array}{l}\text { Subjective global } \\
\text { assessment (SGA) }\end{array}$ & $\begin{array}{l}\text { Medical history - changes in recent food/fluid intake, } \\
\text { weight change, gastrointestinal tract symptoms, and } \\
\text { functional capacity. Physical examination-assesses for } \\
\text { muscle and fat mass wasting and edema. }\end{array}$ & $\begin{array}{l}\text { Based on the degree of loss or change } \\
\text { in each area, an overall rating is } \\
\text { determined as either } \\
\text { Normal well-nourished } \\
\text { Mild/moderate malnutrition } \\
\text { Severe malnutrition }\end{array}$ \\
\hline
\end{tabular}

\subsubsection{SPPB}

The Short Physical Performance Battery (SPPB) is a valid and reliable indicator in older adults of both lower extremity muscle strength and performance. It is relatively quick and easily administered, and includes timed measures of standing balance (in three positions), gait speed (a 4-meter walk), and five chair rises to standing. ${ }^{[76-78]}$ SPPB consists of a summation of these 3 separate equally weighted tests with scores ranging from 0 (not possible) to 4 (best) for a maximum total score of 12 . Scores for each standing balance test range from 0 to 2 , with a score of 0 indicating an inability to balance and a score of 2 indicating the ability to maintain balance in the designated position for a designated time period. Scores for gait speed and completion of the five chair rises each range from 0 to 4 , with the exact scores for each component dependent on the time taken to complete the task. Individuals with low (0 to 6) total scores, versus those with intermediate (7-9) or high (10-12) total scores, are at greater risk of diminished lower body muscle performance including, for example, mobility problems and falls, among other problems.

\subsubsection{DXA \& BIA}

While the measurement of muscle mass is typically not feasible in clinical practice settings, patients who demonstrate reductions in muscle strength or function would benefit from additional measurement of muscle mass. Two of the most commonly used methods to quantify muscle mass include dual X-ray absorptiometry (DXA) and bioelectrical impedance analysis (BIA). DXA measurements involve body scanning at two different alternating energy levels using low-dose X-rays. DXA is expensive and relatively large to house in a clinical setting. Reimbursement for DXA from insurance is also variable. DXA, however, is commonly 
used to measure bone density for the diagnosis of osteopenia/osteoporosis in older adults. Thus, when feasible, coupling the measurement of bone with muscle mass provides for a more thorough assessment of body composition. In contrast to DXA, BIA is fairly portable and less costly; however, the use of BIA for body composition assessment is also not typically reimbursable by insurance and BIA is not appropriate for use in all patients. BIA determines the opposition to the flow of an electric current through body tissues; this resistance is then used to determine body composition. Prediction equations and adjustments of muscle mass based on body size are employed and compared with "standards".

\section{Prevention \& Management}

Two lifestyle changes-diet and exercise-can help prevent extensive loss and build and/or maintain muscle with aging. Further, because losses in muscle mass, strength, and function often begin to accelerate at about 50 years of age, from a prevention perspective, these lifestyle changes should be discussed with all aging adults.

\subsection{Diet}

The main dietary modification to prevent and manage sarcopenia requires the ingestion of adequate dietary protein each day. Greater muscle protein synthesis and muscle mass and strength have been linked with the ingestion of both a more even distribution of protein among daily meals and a sufficient total amount of protein each day. ${ }^{[79-89]} \mathrm{Di}-$ etary protein intake among most Americans is typically higher at the evening meal versus at breakfast and lunch, and many older adults fail to consume adequate dietary protein. ${ }^{[82,90-93]}$ Nurse practitioners can educate and emphasize to their patients about the importance of eating protein-rich food sources at each meal. Healthy animal protein choices that should be emphasized to patients include eggs, lowfat dairy products (i.e. milk, yogurt and cheeses), fish and seafood, and lean white meats. Good plant protein food sources include lentils, legumes, tofu, seeds, and some nuts. (Note, while grains and vegetables also provide protein, the amount provided is relatively small, less than about 3 grams per serving). To maximize protein synthesis, consumption of at least $25 \mathrm{~g}$ of protein per meal is recommended, although more or less protein may be needed depending on a person's body weight and medical conditions. ${ }^{[94,95]}$ Additionally, because foods from other food groups also provide essential vitamins and minerals needed for muscle and overall health, consumption of vegetables, fruits, and whole grains should also be promoted. When possible, Nurse Practitioners should work with the dietitian to optimize the diet plan for patients, especially those with other co-morbidities.

\subsection{Exercise}

Complementary to the potential modifications of patients' eating patterns (e.g. diet), assisting them to alter their physical activity (i.e. exercise) behaviors could also be beneficial in an individual's health, functional independence, and quality of life. Specifically, guiding individuals with sarcopenia to endorse a program focused on increasing their muscular fitness, especially muscular hypertrophy would be desirable. Current government guidelines for "older adults" suggest that they participate in two types of activity: "aerobic and muscle-strengthening". [96] Additionally, these same types of guidelines suggest that older adults at risk of falls should include "balance training". [96] The overall activity goals to improve muscular fitness suggest that "older adults perform muscle-strengthening activities that are moderate or high intensity and involve all major muscle groups on 2 or more days a week".[96,97] Examples of the type of activities that the guidelines validate for muscle-strengthening are:

- Exercises using exercise bands, weight machines, hand-held weights.

- Calisthenics using body weight to provide resistance to movement.

- Digging, lifting, and carrying as part of gardening.

- Carrying groceries.

- Some types of yoga exercises.

- Some types of Tai chi exercises.

Westcott points out that "resistance training can be effective for reversing muscle loss and metabolic decline that frequently accompanies inactive aging". ${ }^{[98]}$ With this alone as the rationale, it might be wise to emphasize to individuals diagnosed with sarcopenia to begin a progressive resistance training (PRT) program, specifically to combat the deleterious effects of sarcopenia. The primary goals for this type of exercise program would include increasing muscular fitness, in particular hypertrophy, muscular strength, and power. However, it may be quite an endeavor to include this lifestyle change since it has been estimated that only about $10 \%$ of all older adults participate in any type of PRT program. ${ }^{[99]}$ But, with this type of an exercise program consistently demonstrating an improvement in skeletal muscle mass, strength, and power, it might be worth the challenge.

\section{Conclusions}

Sarcopenia is a disease that can develop in the aging population, is characterized by the loss of skeletal muscle mass, strength and/or function, and is associated with multiple adverse health outcomes. Because the aging population is living longer, we can expect to see the prevalence of sarcopenia increase in parallel. It is important for the nurse 
practitioner to stay abreast of the current diagnosis code(s) and interventions that are available to treat sarcopenia.

Both from a proactive screening approach, as well as a tertiary prevention paradigm, an interprofessional team would be advantageous to assist patients with and at risk of sarcopenia to regain rebuild, and rehabilitate their muscle mass and strength. This approach could also serve to prevent longerterm outcomes of clinical importance such as functional

\section{REFERENCES}

[1] Anker SD, Morley JE, Haehling S. Welcome to the ICD-10 code for sarcopenia. J Cachexia Sarcopenia Muscle. 2016 Oct; 7(5): 512-4. PMid:27891296 https://doi.org/10.1002/jcsm. 12147

[2] Rosenberg IH. Sarcopenia: origins and clinical relevance. J. Nutr. 1997 May; 127(Suppl): 990-1. https ://doi.org/10.1093/jn/1 $27.5 .990 \mathrm{~S}$

[3] Lynch NA, Metter EJ, Lindle RS, et al. Muscle quality. I. Ageassociated differences between arm and leg muscle groups. J Appl Physiol. 1999 Jan; 86(1): 188-94. PMid:9887130 https : //doi .or $\mathrm{g} / 10.1152 / \mathrm{jappl} .1999 .86 .1 .188$

[4] Mitchell WK, Williams J, Atherton P, et al. Sarcopenia, dynapenia, and the impact of advancing age on human skeletal muscle size and strength: a quantitative review. Front Physiol. 2012 Jul; (3): 260.

[5] Goodpaster BH, Park SW, Harris TB, et al. The loss of skeletal muscle strength, mass, and quality in older adults: the health, aging and body composition study. J Gerontol A Biol Sci Med Sci. 2006 Oct; 61(10): 1059-64.

[6] Hughes VA, Frontera WR, Wood M, et al. Longitudinal muscle strength changes in older adults: influence of muscle mass, physical activity, and health. J Gerontol A Biol Sci Med Sci. 2001 May; 56(5): B209-17.

[7] Cruz-Jentoft AJ, Baeyens JP, Bauer JM, et al. Sarcopenia: European consensus on definition and diagnosis. Report of the European working group on sarcopenia in older people. Age Ageing. $2010 \mathrm{Jul}$; 39(4): 412-23.

[8] Cruz-Jentoft AJ, Landi F, Schneider SM, et al. Prevalence of and interventions for sarcopenia in ageing adults: a systematic review. Report of the international sarcopenia initiative (EWGSOP and IWGS). Age Ageing. 2014 Nov; 43(6): 748-59.

[9] Fielding RA, Vellas B, Evans WJ, et al. Sarcopenia: an undiagnosed condition in older adults. Current consensus definition: prevalence, etiology, and consequences. International working group on sarcopenia. J Am Med Dir Assoc. 2011 May; 12(4): 249-56.

[10] Hairi NN, Cumming RG, Naganathan V, et al. Loss of muscle strength, mass (sarcopenia), and quality (specific force) and its relationship with functional limitation and physical disability: the concord health and ageing in men project. J Am Geriatr Soc. 2010 Nov; 58(11): 2055-62.

[11] Dam TT, Peters KW, Fragala M, et al. An evidence-based comparison of operational criteria for the presence of sarcopenia. J Gerontol A Biol Sci Med Sci. 2014 May; 69(5): 584-90.

[12] Chen LK, Liu LK, Woo J, et al. Sarcopenia in Asia: consensus report of the asian working group for sarcopenia. J Am Med Dir Assoc. 2014 Feb; (2): 95-101.

Published by Sciedu Press impairment, likelihood of frailty, and even mortality. The challenge is in the discovery and taking a proactive approach to prolong the onset of the aging process as it is related to muscle strength and function. Higher muscle mass is associated with better outcomes and longevity in healthy adults as well as in patients with chronic disease states.

\section{CONFLicts OF INTEREST Disclosure}

The authors declare that there is no conflict of interest.
[13] Graf CE, Pichard C, Herrmann FR, et al. Prevalence of low muscle mass according to body mass index in older adults. Nutrition. 2017 Feb; 34: 124-9.

[14] Janssen I, Heymsfield SB, Ross R. Low relative skeletal muscle mass (sarcopenia) in older persons is associated with functional impairment and physical disability. J Am Geriatr Soc. 2002 May; 50(5): 889-96. PMid:12028177 https://doi.org/10.1046/j.1532-5 415.2002.50216.x

[15] Müller MJ, Geisler C, Pourhassan M, et al. Assessment and definition of lean body mass deficiency in the elderly. Eur J Clin Nutr. 2014 Nov; 68(11): 1220-7.

[16] Batsis JA, Mackenzie TA, Barre LK, et al. Sarcopenia, sarcopenic obesity and mortality in older adults: results from the national health and nutrition examination survey III. Eur J Clin Nutr. 2014 Sep; 68(9): 1001-7.

[17] Janssen I, Shepard DS, Katzmarzyk PT, et al. The healthcare costs of sarcopenia in the United States. J Am Geriatr Soc. 2004 Jan; 52(1): 80-5.

[18] Morley JE, Malmstrom TK. Frailty, sarcopenia, and hormones. Endocrinol. Metab. Clin. North Am. 2013 Jun; 42(2): 391-405.

[19] Tarantino U, Baldi J, Celi M, et al. Osteoporosis and sarcopenia: the connections. Aging Clin Exp Res. 2013 Oct; 25(Suppl 1): 93-5.

[20] Pasco JA, Williams LJ, Jacka FN, et al. Sarcopenia and the common mental disorders: a potential regulatory role of skeletal muscle on brain function? Curr Osteoporos Rep. 2015 Oct; 13(5): 351-7.

[21] Rantanen T, Guralnik JM, Foley D, et al. Midlife hand grip strength as a predictor of old age disability. JAMA. 1999 Feb; 281(6): 558-60.

[22] Uusi-Rasi K, Kannus P, Karinkanta S, et al. Study protocol for prevention of falls: a randomized controlled trial of effects of vitamin D and exercise on falls prevention. BMC Geriatr. 2012 Mar; 12: 12.

[23] Zoltick ES, Sahni S, McLean RR, et al. Dietary protein intake and subsequent falls in older men and women: the Framingham Study. J Nutr Health Aging. 2011 Feb; 15(2): 147-52.

[24] Castillo EM, Goodman-Gruen D, Kritz-Silverstein D, et al. Sarcopenia in elderly men and women: the rancho bernardo study. Am J Prev Med. 2003 Oct; 25(3): 226-31.

[25] Sayer AA, Syddall HE, Martin HJ, et al. Is grip strength associated with health-related quality of life? Findings from the hertfordshire cohort study. Age Ageing. 2006 Jul; 35(4): 409-15.

[26] Kramer IF, Snijders T, Smeets JSJ, et al. Extensive type II muscle fiber atrophy in elderly female hip fracture patients. J Gerontol A Biol Sci Med Sci. 2017 Oct; 72(10): 1369-75.

[27] Fried LP, Tangen CM, Walston J, et al. Frailty in older adults: evidence for a phenotype. J Gerontol A Biol Sci Med Sci. 2001 Mar; 56(3): M146-56. 
[28] Cesari M, Leeuwenburgh C, Lauretani F, et al. Frailty syndrome and skeletal muscle: results from the invecchiare in chianti study. Am J Clin Nutr. 2006; 83(5): 1142-8. PMid:16685058 https: //doi.org/10.1093/ajcn/83.5.1142

[29] Landi F, Cruz-Jentoft AJ, Liperoti R, et al. Sarcopenia and mortality risk in frail older persons aged 80 years and older: results from ilSIRENTE study. Age Ageing. 2013 Mar; 42(2): 203-9.

[30] Fiatarone Singh MA, Singh NA, Hansen RD, et al. Methodology and baseline characteristics for the sarcopenia and hip fracture study: a 5-year prospective study. J Gerontol A Biol Sci Med Sci. 2009 May; 64(5): 568-74.

[31] Gariballa S, Alessa A. Sarcopenia: prevalence and prognostic significance in hospitalized patients. Clin Nutr. 2013 Oct; 32(5): 772-6. PMid:23395102

[32] Norman K, Stobäus N, Gonzalez MC, et al. Hand grip strength: outcome predictor and marker of nutritional status. Clin Nutr. 2011 Apr; 30(2): 135-42.

[33] Bohannon RW, Maljanian R, Ferullo J. Mortality and readmission of the elderly one year after hospitalization for pneumonia. Aging Clin Exp Res. 2004 Feb; 16(1): 22-5. PMid:15132287 https : //doi.org/10.1007/BF03324527

[34] Guo CB, Zhang W, Ma DQ, et al. Hand grip strength: an indicator of nutritional state and the mix of postoperative complications in patients with oral and maxillofacial cancers. Br J Oral Maxillofac Surg. 1996 Aug; 34(4): 325-7.

[35] Hunt DR, Rowlands BJ, Johnston D. Hand grip strength-a simple prognostic indicator in surgical patients. JPEN J Parenter Enteral Nutr. 1985; 9(6): 701-4. PMid:4068194

[36] Kerr A, Syddall HE, Cooper C, et al. Does admission grip strength predict length of stay in hospitalised older patients? Age Ageing 2006 Jan; 35(1): 82-4.

[37] Arrieta O, De la Torre-Vallejo M, López-Macías D, et al. Nutritional status, body surface, and low lean body mass/body mass index are related to dose reduction and severe gastrointestinal toxicity induced by afatinib in patients with non-small cell lung cancer. Oncologist. 2015; 20(8): 967-74. PMid:26173839 https ://doi .org/10.163 4/theoncologist.2015-0058

[38] Arrieta O, Michel Ortega RM, Villanueva-Rodríguez G, et al. Association of nutritional status and serum albumin levels with development of toxicity in patients with advanced non-small cell lung cancer treated with paclitaxel-cisplatin chemotherapy: a prospective study. BMC Cancer. 2010 Feb; 10: 50.

[39] Ali R, Baracos VE, Sawyer MB, et al. Lean body mass as an independent determinant of dose-limiting toxicity and neuropathy in patients with colon cancer treated with FOLFOX regimens. Cancer Med. 2016; 5(4): 607-16. PMid:26814378 https ://doi.org/10 $.1002 /$ cam4.621

[40] Harada K, Suzuki S, Ishii H, et al. Impact of skeletal muscle mass on long-term adverse cardiovascular outcomes in patients with chronic kidney disease. Am J Cardiol. 2017 Apr; 119(8): 1275-80.

[41] Lavie CJ, De Schutter A, Patel DA, et al. Body composition and survival in stable coronary heart disease: impact of lean mass index and body fat in the "obesity paradox". J Am Coll Cardiol. 2012; 60(15): 1374-80. PMid:22958953 https://doi.org/10.1016/j . jacc. 2012.05 .037

[42] dos Santos MR, Saitoh M, Ebner N, et al. Sarcopenia and endothelial function in patients with chronic heart failure: results From the studies investigating comorbidities aggravating heart failure (SICA-HF). J Am Med Dir Assoc. 2017 Mar; 18(3): 240-5.

[43] Buford TW, Anton SD, Judge AR, et al. Models of accelerated sarcopenia: critical pieces for solving the puzzle of age-related muscle atrophy. Ageing Res Rev. 2010 Oct; 9(4): 369-83.
[44] Hirai K, Ookawara S, Morishita Y. Sarcopenia and physical inactivity in patients with chronic kidney disease. Nephrourol Mon. 2016 May; 8(3): e37443. PMid:27570755

[45] Patel SS, Molnar MZ, Tayek JA, et al. Serum creatinine as a marker of muscle mass in chronic kidney disease: results of a cross-sectional study and review of literature. J Cachexia Sarcopenia Muscle. 2013; 4(1): 19-29. PMid:22777757 https://doi.org/10.1007/s135 39-012-0079-1

[46] Molnar MZ, Streja E, Kovesdy CP, et al. Associations of body mass index and weight loss with mortality in transplant-waitlisted maintenance hemodialysis patients. Am J Transplant. 2011; 11(4): 725-36. PMid:21446975 https://doi.org/10.1111/j.1600-6143.20 11.03468. $\mathrm{x}$

[47] Jones SE, Maddocks M, Kon SSC, et al. Sarcopenia in COPD: prevalence, clinical correlates and response to pulmonary rehabilitation. Thorax. 2015 Mar; 70(3): 213-8.

[48] Vestbo J, Prescott E, Almdal T, et al. Body mass, fat-free body mass, and prognosis in patients with chronic obstructive pulmonary disease from a random population sample: findings from the copenhagen city heart study. Am J Respir Crit Care Med. 2006 Jan; 173(1): 79-83.

[49] Marquis K, Debigaré R, Lacasse Y, et al. Midthigh muscle crosssectional area is a better predictor of mortality than body mass index in patients with chronic obstructive pulmonary disease. Am J Respir Crit Care Med. 2002 Sep; 166(6): 809-13.

[50] Malmstrom TK, Miller DK, Simonsick EM, et al. SARC-F: a symptom score to predict persons with sarcopenia at risk for poor functional outcomes. J Cachexia Sarcopenia Muscle. 2016; 7(1): 28-36. PMid:27066316 https ://doi.org/10.1002/jcsm. 12048

[51] Woo J, Leung J, Morley JE. Validating the SARC-F: a suitable community screening tool for sarcopenia? J Am Med Dir Assoc. 2014 Sep; 15(9): 630-4. PMid:24947762

[52] Guyonnet S, Rolland Y. Screening for malnutrition in older people. Clin Geriatr Med. 2015 Aug; 31(3): 429-37. PMid:26195101 https://doi.org/10.1016/j.cger.2015.04.009

[53] Phillips MB, Foley AL, Barnard R, et al. Nutritional screening in community-dwelling older adults: a systematic literature review. Asia Pac J Clin Nutr. 2010; 19(3): 440-9.

[54] Rubenstein LZ, Harker JO, Salvà A, et al. Screening for undernutrition in geriatric practice: developing the short-form mini-nutritional assessment (MNA-SF). J Gerontol A Biol Sci Med Sci. 2001 Jun; 56(6): M366-72.

[55] Kaiser MJ, Bauer JM, Ramsch C, et al. Validation of the mini nutritional assessment short-form (MNA $\mathbb{R}-\mathrm{SF})$ : A practical tool for identification of nutritional status. J Nutr Health Aging. 2009 Nov; 13(9): 782.

[56] Kaiser MJ, Bauer JM, Rämsch C, et al. Frequency of malnutrition in older adults: a multinational perspective using the mini nutritional assessment. J Am Geriatr Soc. 2010 Sep; 58(9): 1734-8.

[57] Poulia KA, Yannakoulia M, Karageorgou D, et al. Evaluation of the efficacy of six nutritional screening tools to predict malnutrition in the elderly. Clin Nutr. 2012 Jun; 31(3): 378-85.

[58] Vellas B, Villars H, Abellan G, et al. Overview of the MNA@-its history and challenges/discussion. J Nutr Health Aging. 2006; 10(6): 456. http://search.proquest. com/openview/4df23b3852f 97bb8a92644cd802c9f5f / ?pq-origsite=gscholar\&cbl=2 8850

[59] Anthony PS. Nutrition screening tools for hospitalized patients. Nutr Clin Pract. 2008; 23(4): 373-82. PMid:18682588 https : //doi.org/10.1177/0884533608321130

[60] Stratton RJ, Hackston A, Longmore D, et al. Malnutrition in hospital outpatients and inpatients: prevalence, concurrent validity and ease of use of the "malnutrition universal screening tool"("MUST") for 
adults. Br J Nutr. 2004; 92(5): 799-808. PMid:15533269 https: //doi.org/10.1079/BJN20041258

[61] Detsky AS, McLaughlin JR, Baker JP, et al. What is subjective global assessment of nutritional status? JPEN J Parenter Enteral Nutr. 1987 Jan; 11(1): 8-13.

[62] Detsky AS, Smalley PS, Chang J. Is this patient malnourished? JAMA. 1994; 271(1): 54-8. https://doi.org/10.1001/jama .1994 .03510250070038

[63] Norman K, Schütz T, Kemps M, et al. The subjective global assessment reliably identifies malnutrition-related muscle dysfunction. Clin Nutr. 2005 Feb; 24(1): 143-50. PMid:15681112 https : //doi.org/10.1016/j.clnu.2004.08.007

[64] White JV, Guenter P, Jensen G, et al. Consensus statement of the academy of nutrition and dietetics/american society for parenteral and enteral nutrition: characteristics recommended for the identification and documentation of adult malnutrition (undernutrition). J Acad Nutr Diet. 2012; 112(5): 730-8. PMid:22709779 https://doi.org/10.1016/j.jand.2012.03.012

[65] Benítez Brito N, Suárez Llanos JP, Fuentes Ferrer M, et al. Relationship between mid-upper arm circumference and body mass index in inpatients. PLoS One. 2016 Aug; 11(8): e0160480.

[66] Powell-Tuck J, Hennessy EM. A comparison of mid upper arm circumference, body mass index and weight loss as indices of undernutrition in acutely hospitalized patients. Clin Nutr. 2003 Jun; 22(3): 30712. https://doi.org/10.1016/S0261-5614(03)00009-8

[67] Blackburn GL, Bistrian BR, Maini BS, et al. Nutritional and metabolic assessment of the hospitalized patient. JPEN J Parenter Enteral Nutr. 1977; 1(1): 11-22. https://doi.org/10.1177/01 4860717700100101

[68] Thomas DR. Sarcopenia. Clin Geriatr Med. 2010 May; 26(2): 331-46. PMid:20497850

[69] Studenski SA, Peters KW, Alley DE, et al. The FNIH sarcopenia project: rationale, study description, conference recommendations, and final estimates. J Gerontol A Biol Sci Med Sci. 2014 May; 69(5): 547-58.

[70] Hardy R, Cooper R, Shah I, et al. Is chair rise performance a useful measure of leg power? Aging Clin Exp Res. 2010 Oct; 22(5-6): 412-8.

[71] Pinheiro PA, Carneiro JAO, Coqueiro RS, et al. Chair stand test as simple tool for sarcopenia screening in elderly women. J Nutr Health Aging. 2015 Nov; 1-4.

[72] Rikli RE, Jones CJ. J Aging Phys Act. 1999 Apr; 7(2): 129-61.

[73] Bohannon RW. Reference values for the timed up and go test: a descriptive meta-analysis. J Geriatr Phys Ther. 2006 Aug; 29(2): 64. Available from: http: //journals.lww.com/jgpt/Abstract/2006/08000/Refere nce_Values_for_the_Timed_Up_and_Go_Test__A.4.aspx

[74] Muscaritoli M, Anker SD, Argilés J, et al. Consensus definition of sarcopenia, cachexia and pre-cachexia: Joint document elaborated by special interest groups (SIG) "cachexia-anorexia in chronic wasting diseases" and "nutrition in geriatrics." Clin Nutr. 2010 Apr; 29(2): 154-9.

[75] Bischoff HA, Stähelin HB, Monsch AU, et al. Identifying a cut-off point for normal mobility: a comparison of the timed "up and go" test in community-dwelling and institutionalised elderly women. Age Ageing. 2003 May; 32(3): 315-20.

[76] Cooper C, Fielding R, Visser M, et al. Tools in the assessment of sarcopenia. Calcif Tissue Int. 2013 Sep; 93(3): 201-10.

[77] Cesari M, Kritchevsky SB, Newman AB, et al. Added Value of Physical Performance Measures in Predicting Adverse Health-Related Events: Results from the Health, Aging and Body Composition
Study. J Am Geriatr Soc [Internet]. 2009; 57(2): 251-9. Available from: http://onlinelibrary.wiley.com/doi/10.1111/ j.1532-5415.2008.02126.x/full

[78] Guralnik JM, Simonsick EM, Ferrucci L, et al. A short physical performance battery assessing lower extremity function: association with self-reported disability and prediction of mortality and nursing home admission. J Gerontol. 1994; 49(2): M85-94.

[79] Isanejad M, Mursu J, Sirola J, et al. Association of protein intake with the change of lean mass among elderly women: the osteoporosis risk factor and prevention-fracture prevention study (OSTPRE-FPS). J Nutr Sci. 2015.

[80] Isanejad M, Mursu J, Sirola J, et al. Dietary protein intake is associated with better physical function and muscle strength among elderly women. Br J Nutr. 2016 Apr; 115(7): 1281-91.

[81] Meng X, Zhu K, Devine A, et al. A 5-year cohort study of the effects of high protein intake on lean mass and BMC in elderly postmenopausal women. J Bone Miner Res. 2009 Nov; 24(11): 1827-34.

[82] Houston DK, Nicklas BJ, Ding J, et al. Dietary protein intake is associated with lean mass change in older, community-dwelling adults: the Health, Aging, and Body Composition (Health ABC) Study. Am J Clin Nutr. 2008 Jan; 87(1): 150-5.

[83] Murphy CH, Oikawa SY, Phillips SM. Dietary Protein to maintain muscle mass in aging: a case for per-meal protein recommendations. J Frailty Aging. 2016; 5(1): 49-58. PMid:26980369

[84] Loenneke JP, Loprinzi PD, Murphy CH, et al. Per meal dose and frequency of protein consumption is associated with lean mass and muscle performance. Clin Nutr. 2016 Dec; 35(6): 1506-11.

[85] Norton C, Toomey C, McCormack WG, et al. Protein supplementation at breakfast and lunch for 24 weeks beyond habitual intakes increases whole-body lean tissue mass in healthy older adults-3. J Nutr. 2016 Jan; 146(1): 65-9.

[86] Volpi E, Campbell WW, Dwyer JT, et al. Is the optimal level of protein intake for older adults greater than the recommended dietary allowance? J Gerontol A Biol Sci Med Sci. 2013 Jun; 68(6): 677-81.

[87] Paddon-Jones D, Leidy H. Dietary protein and muscle in older persons. Curr Opin Clin Nutr Metab Care. 2014 Jan; 17(1): 5-11. PMid:24310053 https://doi.org/10.1097/MC0.0000000000 000011

[88] Mamerow MM, Mettler JA, English KL, et al. Dietary protein distribution positively influences $24-\mathrm{h}$ muscle protein synthesis in healthy adults-3. J Nutr. 2014 Jun; 144(6): 876-80.

[89] Farsijani S, Payette H, Morais JA, et al. Even mealtime distribution of protein intake is associated with greater muscle strength, but not with 3-y physical function decline, in free-living older adults: the quebec longitudinal study on nutrition as a determinant of successful aging (NuAge study). Am J Clin Nutr. 2017; 106(1): 113-24. PMid:28515070 https://doi.org/10.3945/ajcn.116.14655 5

[90] Berner LA, Becker G, Wise M, Doi J. Characterization of dietary protein among older adults in the United States: amount, animal sources, and meal patterns. J Acad Nutr Diet. 2013 Jun; 113(6): 80915. PMid:23491327 https://doi.org/10.1016/j.jand. 2013. 01.014

[91] Fulgoni VL. Current protein intake in America: analysis of the national health and nutrition examination survey, 2003-2004. Am J Clin Nutr. 2008 May; 87(5): 1554S-1557S. PMid:18469286

[92] USDA ARS: energy intake: percentages of energy from protein, carbohydrate, fat and alcohol by gender and age, what we eat in America, NHANES 2009-2010. Washington D.C: United States Department of Agriculture Agriculture Research Service. Available from: http://www.ars.usda.gov/ba/bhnrc/fsrg 
[93] Tieland M, Borgonjen-Van den Berg KJ, van Loon LJC, et al. Dietary protein intake in community-dwelling, frail, and institutionalized elderly people: scope for improvement. Eur J Nutr. 2012 Mar; 51(2): 173-9.

[94] Paddon-Jones D, Rasmussen BB. Dietary protein recommendations and the prevention of sarcopenia. Curr Opin Clin Nutr Metab Care. 2009 Jan; 12(1): 86-90. PMid:19057193 https ://doi .org/10.1 097/MCD. 0b013e32831cef8b

[95] Bauer J, Biolo G, Cederholm T, et al. Evidence-based recommendations for optimal dietary protein intake in older people: a position paper from the PROT-AGE Study Group. J Am Med Dir Assoc. 2013 Aug; 14(8): 542-59.

[96] U.S. Department of Health and Human Services. Physical Activity
Guidelines for Americans. Washington, D.C: U.S. Government Printing Office, 2008. Available from: http://health.gov/paguide lines/guidelines/chapter5.aspx

[97] American College of Sports Medicine. American College of Sports Medicine position stand. Progression models in resistance training for healthy adults. Med Sci Sports Exerc. 2009 Mar; 41(3): 687-708. PMid:19204579

[98] NSCA-National Strength \& Conditioning Association, Jacobs P. NSCA's essentials of training special populations. Human Kinetics Publishers; 2017. 528 p.

[99] Seguin R, Nelson ME. The benefits of strength training for older adults. Am J Prev Med. 2003 Oct; 25(3): 141-9. https ://doi . or g/10.1016/S0749-3797 (03)00177-6 